\title{
UNA NUEVA SÍNTESIS INTERPRETATIVA DEL TRIENIO LIBERAL EN SU BICENTENARIO
}

\section{A NEW INTERPRETATIVE SYNTHESIS OF THE LIBERAL TRIENNIUM 200 YEARS AFTER}

\author{
Juan Luis Simal \\ Universidad Autónoma de Madrid
}

Recensión de / Review of: Pedro Rújula y Manuel Chust, El Trienio liberal en la monarquía hispánica. Revolución e independencia (1820-1823), Los Libros de la Catarata, Madrid, 2020, 190 páginas.

Entre las muchas cosas que nos ha hurtado el año 2020 se encuentra la celebración del bicentenario del inicio del Trienio Liberal, el régimen constitucional establecido en España entre 1820 y 1823. Cierto es que en España no estaban previstos grandes actos conmemorativos de carácter oficial, a diferencia, por ejemplo, de Portugal, donde en octubre de 2020 debería haberse celebrado en Lisboa un congreso internacional patrocinado por la Asamblea de la República en conmemoración del proceso político de rasgos similares iniciado en el país vecino también en 1820. Sin embargo, sí que han tenido lugar en España varios encuentros con desigual patrocinio institucional antes del parón de la actividad académica forzado por la pandemia de la covid-19, algunos de ellos organizados por los autores de este libro, Pedro Rújula (Universidad de Zaragoza) y Manuel Chust (Universitat Jaume I). Además, a lo largo de 2020 y 2021 han aparecido un destacado número de monografias, artículos y dosieres de revista entre ellos el de Historia Constitucional ( $\mathrm{n}^{\circ} 21$ ) - dedicados a una de las etapas de la historia española más fascinantes, pero menos conocidas para el gran público. En cualquier caso, lo cierto es que, por distintos motivos, el bicentenario del Trienio ha carecido de la repercusión pública que tuvo la celebración del 200 aniversario de la Constitución de Cádiz, a pesar de que estos años fueron claves para el desarrollo práctico del código doceañista. Esto no quiere decir, sin embargo, que el bicentenario de 1820 no pueda brindar la ocasión para no solo actualizar conocimientos, sino también repensar un importante periodo de la historia española, europea y americana. Este libro es buena prueba de ello.

Hasta ahora, los interesados en el estudio del Trienio debían acudir a la pionera obra, ya algo envejecida, de Alberto Gil Novales, autor tanto del brevísimo libro El Trienio Liberal (1980) - reeditado en 2020 por Prensas de la Universidad de Zaragoza con estudio preliminar de Ramon Arnabat - como de los monumentales Las sociedades patrióticas (1975) y Diccionario biográfico del Trienio Liberal (1991). A estas obras podrian añadirse varios estudios de escala regional o local (como los de M. C. Romeo Mateo sobre Valencia, los de Arnabat sobre Cataluña, o Jordi Roca Vernet sobre Barcelona), además de un libro de Emilio La Parra con un título algo engañoso - Los Cien Mil Hijos de San Luis (2007) - ya que, aunque se centraba en "el ocaso del primer impulso liberal en España", incluía de hecho un apreciable análisis del periodo constitucional que sería trasladado por el autor a la biografia de Fernando VII que con gran repercusión publicó en 2018. 
El libro que ahora publican Rújula y Chust tiene, por tanto, el propósito de servir de sintesis actualizada del periodo, pero también, y esto es importante, de plantear una renovada agenda historiográfica. La obra es al mismo tiempo una excelente introducción a un periodo que carecía de una monografia actualizada y, además, un libro con propuestas propias. La más evidente, y la que probablemente más recorrido tendrá en el futuro, es la inclusión de un análisis que incorpora de manera central el escenario americano (y filipino) al peninsular. Para ello, el libro recurre a la obra de destacados autores que en los últimos años han renovado la comprensión transatlántica del Trienio (como Jaime E. Rodriguez O., Ivana Frasquet, Xiomara Avendaño, Rodrigo Moreno, Núria Sala, Ascensión Martínez Riaza o Víctor Peralta). Así, no se trata tan solo de contemplar la repercusión que tuvo en España la "consumación" de la independencia de la América continental, o de analizar las formas a través de las cuales los liberales peninsulares trataron de resolver la "cuestión americana", sino de estudiar los complejos acontecimientos que a partir de la restauración constitucional de 1820 tuvieron lugar en unos territorios americanos y asiáticos en los que las instituciones constitucionales se desplegaron de manera notable, y que influyeron destacadamente en las formas y vias que la independencia terminó tomando. Con la excepción de Chile, el Río de la Plata y Paraguay - que ya habían alcanzado su independencia de facto años antes - y de Cuba y Puerto Rico - que se mantendrían en el seno de la Monarquía - el resto de los territorios americanos caminaron hacia su emancipación entre 1820 y 1823, confirmada tras las batallas de Junin y Ayacucho en 1824.

Asimismo, el libro incorpora las más recientes investigaciones sobre el liberalismo y la contrarrevolución en su dimensión peninsular, y lo hace a través de una narración ágil que introduce elegantes reflexiones analiticas sobre las múltiples dimensiones que adquirió a partir del 1 de enero de 1820 el despliegue de la modernidad política liberal, así como de la igualmente heterogénea respuesta reaccionaria que generó. El libro muestra que ambos fenómenos contaron con una amplia participación popular.

Como viene siendo argumentado recientemente por varios especialistas, los autores rechazan que el régimen constitucional del Trienio fuera un proyecto político condenado al fracaso o de alcance limitado. Esta es una visión en la que habian coincidido tanto la historiografia decimonónica de carácter moderadoconservador como la de carácter liberal-progresista (y por supuesto la carlistatradicionalista), pero que también había sido un elemento sustancial de las tendencias historiográficas que durante el siglo XX consideraron el liberalismo español como una débil derivación de influencias extranjeras (en el caso de la conocida como "escuela de Navarra") o como un vacilante proceso inacabado o traicionado (en el caso de los historiadores de tendencias marxistas).

Al contrario, Rújula y Chust muestran la fortaleza de un liberalismo con identidad propia al tiempo que presentan el Trienio como un periodo clave en el proceso de politización de la población española e hispanoamericana, que dejó además un notable legado institucional. En su opinión, el Trienio fue "un periodo de manifiesta modernidad y de gran madurez política” (p. 13).

El libro expone y analiza en sus primeros capitulos los hechos sucedidos en la Península, mostrando la vitalidad del debate politico y las dimensiones alcanzadas por la movilización popular. El relato se detiene en el verano de 1822, 
cuando la contrarrevolución comienza a desafiar seriamente la estabilidad del régimen constitucional.

Se abren entonces la narración y el análisis a los acontecimientos que tuvieron lugar en los territorios de ultramar a partir de 1820, destacando el vigor con el que las instituciones constitucionales se desplegaron en América y Filipinas, y las alternativas abiertas por el retorno de buena parte del "realismo" americano al proyecto liberal. De esta forma, se aprecia claramente el potencial que tuvo el constitucionalismo panhispánico para encontrar una vía autonomista de salida al conflicto, que sin embargo fue finalmente truncada. No se trata, pues, de limitarse a enmarcar lo sucedido en América y Filipinas en relación con los acontecimientos peninsulares, sino de exponer también las formas en las que el desafio autonomista americano influyó en la decantación del liberalismo español. El Estado liberal español quedaría marcado por un notable carácter centralizador no solo como consecuencia de sus principios homogeneizadores frente a los privilegios territoriales del Antiguo Régimen, sino también como respuesta a los planteamientos de autogobierno planteados por los diputados americanos en las Cortes del Trienio.

Los autores reclaman, acertadamente, la necesidad de "volver - o ir - a las fuentes primarias críticamente" (p. 13) con el fin de renovar el estudio del periodo y de replantear asunciones y planteamientos heredados. Para ello, el libro emplea impresos de época y colecciones de fuentes primarias compiladas en las décadas siguientes a los acontecimientos, así como publicaciones legislativas oficiales y el Diario de Sesiones de las Cortes, aunque no material de archivo.

Este es un libro voluntariamente sintético. En menos de 200 páginas no es posible tratar en detalle las múltiples dimensiones del Trienio, y una de las menos desarrolladas es su impacto europeo, apenas tratado en lo relacionado con la política diplomática de las potencias reaccionarias respecto a España. El libro se cierra con una útil cronología, aunque se olvide de alguna fecha clave, como el golpe de Estado del 7 de julio de 1822. Igualmente, se echa de menos una conclusión que recapitule los contenidos y las propuestas del libro, que no son pocas y merecian ser expuestas de forma más rotunda. Por otra parte, el texto presenta algunas erratas que podian haberse evitado.

En definitiva, estamos ante una valiosa actualización de la historiografia más reciente, ante una narración que funciona como una excelente introducción al periodo, pero también ante una obra que realiza una apuesta decidida por la necesidad, no solo la conveniencia, de repensar el Trienio como un periodo clave en la historia de España e Hispanoamérica que debe ser estudiado desde una perspectiva transatlántica.

Enviado el (Submission Date): 29/04/2021

Aceptado el (Acceptance Date): 5/05/2021 